\title{
Nephrogenic Systemic Fibrosis
}

\section{Evidence for Oxidative Stress and Bone Marrow-Derived Fibrocytes in Skin, Liver, and Heart Lesions Using a 5/6 Nephrectomy Rodent Model}

\author{
Brent Wagner, ${ }^{\star \dagger}$ Chunyan Tan, ${ }^{\dagger}$ \\ Jeffrey L. Barnes, ${ }^{* \dagger}$ Seema Ahuja, ${ }^{\star \dagger}$ \\ Thomas L. Davis, ${ }^{\ddagger}$ Yves Gorin, ${ }^{\dagger}$ and \\ Fabio Jimenez* \\ From the VA Research, South Texas Veterans Health Care \\ System,* and the Department of Medicine, ${ }^{\dagger}$ University of Texas \\ Health Science Center at San Antonio; and South Texas \\ Dermatopathology, ${ }^{\ddagger}$ San Antonio, Texas
}

Nephrogenic systemic fibrosis (NSF) is associated with gadolinium-based magnetic resonance imaging (MRI) contrast exposure in the setting of acute or chronic renal compromise. It has been proposed that circulating fibrocytes mediate the disease. A study was conducted to determine whether bone marrow-derived fibroblast precursors are involved in contributing to organ fibrosis in MRI contrast-treated rodents with renal insufficiency. Rats status post 5/6 nephrectomy underwent bone marrow transplant from human placental alkaline phosphatase (hPAP)-expressing donors. After engraftment, animals were treated with gadolinium-based MRI contrast $(2.5 \mathrm{mmol} / \mathrm{kg}$ IP), during weekdays for 4 weeks, or an equivalent volume of normal saline. Dermal cellularity in the contrast-treated group was fourfold that of control. Skin cells from the contrast-treated group demonstrated greater hPAP expression with co-expression of pro-collagen I and $\alpha$-smooth muscle actin-positive stress fibers. Donor and host cells expressed CD34. Dihydroethidium staining of skin was greater in the contrast-treated animals, indicating oxidative stress. This was abrogated when the animals were co-administered the superoxide dismutase mimetic tempol. In conclusion, a bone marrow-derived cell population is increased in the dermis of MRI contrast-treated rodents. The cell markers are consistent with fibrocytes mediating the disease. These changes correlate with oxidative stress and expression of Nox4, sugges- tive of a novel therapeutic target. Elucidation of the mechanisms of MRI contrast-induced fibrosis may aid in discovering therapies to this devastating disease. (Am J Pathol 2012, 181:1941-1952; bttp://dx.doi. org/10.1016/j.ajpath.2012.08.026)

Over the last decade, nephrogenic systemic fibrosis (NSF) has been increasingly recognized in patients with renal impairment. NSF is a serious, potentially fatal condition $^{1}$ that is associated with exposure to magnetic resonance imaging contrast agents in settings of impaired glomerular filtration rate (ie, acute kidney injury, chronic and end-stage kidney disease). The affected individual often will present with symmetric pain, pruritis, joint stiffness, tightness, swelling, paresthesias, and/or burning that progresses to a "woody" distal extremity induration and joint contractures that reduce mobility. ${ }^{2}$ Originally described as resembling scleromyxedema histopathologically, ${ }^{3} \mathrm{NSF}$ is clinically differentiated from this disease by facial and neck sparing. ${ }^{4}$ Extracutaneous fibrosis has been reported in several other organs, including heart and liver. ${ }^{5-8}$

The dermis of the NSF-affected individual is characterized by thin spindle-shaped cells and the absence of inflammatory cells. ${ }^{4}$ Lesions demonstrate widespread expression of CD34, a marker for hematopoietic stem and vascular cells. Furthermore, these $\mathrm{CD} 34^{+}$cells express procollagen type I. Given that NSF is a systemic disorder with rapidly developing and symmetric lesions, and often there is a lack of mitotic nuclei observed among these

Supported by a Veterans Administration VISN 17 New Investigator Award (B.W.) and Veterans Administration Career Development Award (B.W.).

Accepted for publication August 23, 2012.

Supplemental material for this article can be found at http://ajp. amjapathol.org or at http://dx.doi.org/10.1016/j.ajpath.2012.08.026.

Address reprint requests to Brent Wagner, M.D., Division of Nephrology, Department of Medicine, UTHSCSA, 7703 Floyd Curl Dr., MC 7882, San Antonio, TX 78229-3900. E-mail: wagnerb@uthscsa.edu. 
spindle cells, a circulating white blood cell, the "fibrocyte"/"alitofibrocyte,"9 has been implicated in mediating the disease. ${ }^{10}$ These fibrocytes may play the central role in skin wound healing ${ }^{11}$ and a number of other sclerotic diseases. They are unique among circulating cells in that they can generate extracellular matrix, and fibrocytes may be bone marrow derived. Fibrocytes, like myofibroblasts during fibrosis, may contribute to excess matrix accumulation, leading to organ failure. ${ }^{12}$

The markers CD34 and procollagen I are not entirely specific to hematopoietic-derived cells. ${ }^{13}$ Therefore we examined the contribution of bone marrow-derived cells to the pathological lesions of skin in a rodent model of NSF. Rats with 5/6 nephrectomies modeled chronic kidney disease followed by lethal irradiation and salvage bone marrow transplant from donors with a stable genetic marker human placental alkaline phosphatase (hPAP). ${ }^{14}$ Animals were treated with gadolinium-based contrast (gadodiamide/caldiamide [Omniscan]) and monitored for weight and gross dermatologic changes. A high expression of the bone marrow marker in skin (but not in liver or heart) with CD34 and procollagen I was detected. Furthermore, this was correlated with signs of oxidative stress and an NADPH oxidase homolog, Nox4, that has been associated with many fibrotic processes. ${ }^{15}$ This work provides experimental proof that circulating, bone marrow-derived cells are involved in NSF, and suggests that Nox4 may be a mediator of the disease as well as a novel therapeutic target.

\section{Materials and Methods}

\section{Animals and Transplantation}

Female Fischer 344 rats $(n=15)$ underwent a full rightsided uninephrectomy, followed by ligation of two-thirds

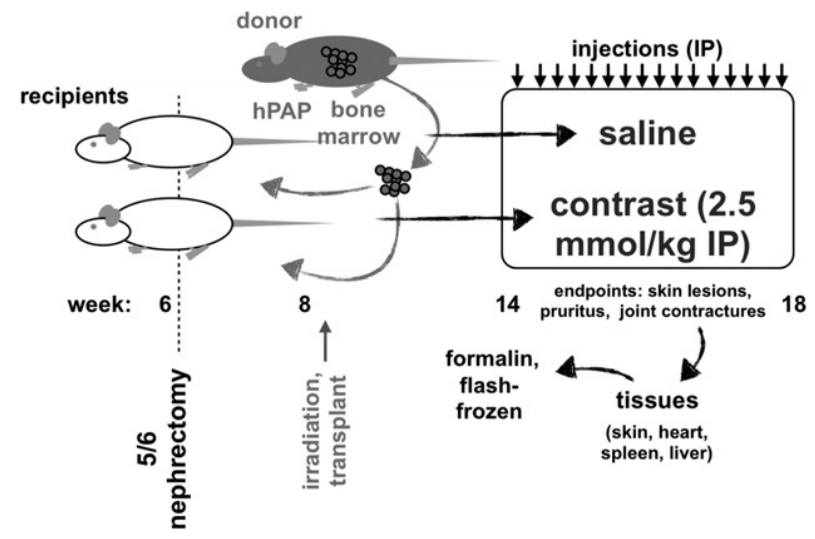

Figure 1. Fischer 344 rats status post a full right-sided uninephrectomy and ligation of two-thirds of the left renal arteries (hence $5 / 6$ "nephrectomy") were used unless otherwise indicated. Rodents underwent lethal irradiation followed by salvage bone marrow transplantation from transgenic donor animals expressing human placental alkaline phosphatase (hPAP). This allowed detection of bone marrow-derived cells in various tissues by immunohistochemistry. After 2 to 6 weeks for recovery, one group of animals was administered gadodiamide MRI contrast (Omniscan, $2.5 \mathrm{mmol} / \mathrm{kg}$ i.p.) during weekdays for 4 weeks. ${ }^{16}$ Control animals received an equivalent volume of saline. At the endpoint, animals were sacrificed, and tissues were collected, flash frozen, and formalin fixed. of renal arteries on the contralateral side at $8 \pm 1$ week of age (Figure 1). Two weeks after the partial nephrectomy, animals underwent lethal irradiation (900 Rad, Gammacell 40; Atomic Energy of Canada Limited, Mississauga, ON, Canada). Bone marrow cells were harvested from hPAP-expressing Fischer 344 male rats (a gift from Dr. Eric Sandgren, University of Wisconsin $)^{14}$ and administered $\left(1 \times 10^{7}\right.$ cells $)$ to the females intravenously (i.v.). After several weeks for engraftment, experimental animals $(n=9)$ were administered gadodiamide (General Electric HealthCare, Little Chalfont, UK), $2.5 \mathrm{mmol} / \mathrm{kg}$ intraperitoneally (i.p.) on weekdays for 4 weeks or were given an equivalent volume of saline $(n=6) .{ }^{16}$ All experimental procedures and protocols were in accordance with the Guide for the Care and Use of Laboratory Animals published by the NIH and approved by the Institutional Animal Care and Use Committee (IACUC).

\section{Alkaline Phosphatase Assay}

The expression of human placental alkaline phosphatase (hPAP) in donors and animals and the chimerism of recipients was validated before and 2 to 4 weeks after bone marrow transplantation, respectively, with an in vitro alkaline phosphatase assay. ${ }^{17}$ Blood was collected from tails. One drop of blood was placed on Whatman filter paper submerged in reaction substrate buffer containing nitroblue tetrazolium reagent. Intense blue staining indicated hPAP expression.

\section{Endpoints}

Endpoints were as follows: i) weight loss of $10 \%$, ii) the dermatological findings previously described (reddening, fur loss, scab formation, or ulceration), ${ }^{16}$ or iii) completion of 4 weeks of contrast treatment. Animals were examined daily for any signs of NSF-like lesions (eg, gross skin changes). Skin thickness was measured at the thoracic, mid-, and lumbar back with digital calipers (VWR, Radnor, PA). Under isoflurane anesthesia, the animals were sacrificed by exsanguination.

Subsequent experiments compared the effect of administration of the antioxidant tempol (Calbiochem, San Diego, CA), in the drinking water $(1 \mathrm{mmol} / \mathrm{L})$, on skin pathology. Female Fischer 344 rats (Charles River, Wilmington, MA) underwent $5 / 6$ nephrectomies at 8 weeks of age. Animals were randomized to control $(n=4)$, MRI contrast $(n=4)$, or MRI contrast with tempol $(n=4)$. After 3 weeks, animals were sacrificed.

\section{Tissue Fixation, Sectioning, and Histology}

Flaps of midline posterior-dorsal skin were dissected off the underlying fascia, and sliced into equal pieces. Some were flash frozen for immunohistochemistry and immunoblot specimens. Remnant pieces were fixed in 10\% neutral buffered formalin (Richard-Allan Scientific, Kalamazoo, MI) overnight, followed by $70 \%$ ethanol. Sections were paraffin embedded, sectioned, and stained with hematoxylin and eosin or Masson's trichrome. Nuclei counts were performed in dermal lesions in areas lacking 
Table 1. Immunofluorescence Stain Synopsis

\begin{tabular}{|c|c|c|c|}
\hline Marker & Dilution & Company & City, State \\
\hline Collagen I & $1: 50$ & Abcam & Cambridge, MA \\
\hline Collagen IV & $1: 50$ & Abcam & \\
\hline Factor XIIIa & $1: 20$ & Abcam & \\
\hline TGF- $\beta 1$ & $1: 100$ & Abcam & \\
\hline Cathepsin L ( $\mathrm{H}-80)$ & $1: 100$ & Santa Cruz Biotechnology & Santa Cruz, CA \\
\hline CD34 & $1: 10$ & Santa Cruz Biotechnology & \\
\hline Procollagen I (N-18) & $1: 10$ & Santa Cruz Biotechnology & \\
\hline$\alpha$-SMA & $1: 200$ & Sigma-Aldrich & St. Louis, MO \\
\hline hPAP & $1: 400$ & Sigma-Aldrich & \\
\hline
\end{tabular}

follicular epithelium. Three random, dermal areas of 5- $\mu \mathrm{m}$ sections of H\&E-stained skin were digitally photographed using a $\times 2.5$ ocular and $\times 40$ objective. The total number of dermal nuclei (excluding epithelial and endothelial cells) was counted. The paraffin-embedded H\&E and trichrome-stained sections were examined in a blinded fashion by a dermatopathologist (T.D.).

\section{Immunofluorescence}

Frozen 5- to 6- $\mu \mathrm{m}$ sections of skin were air dried for 1 hour, fixed in cold acetone, rehydrated, blocked (0.5 $\mathrm{mg} / \mathrm{mL}$ donkey IgG, 15 minutes), and incubated with the primary antibody for 30 minutes, washed, followed by incubation with conjugated secondary. To detect more than one protein marker in the same section, dual-label immunofluorescence was conducted as previously described. ${ }^{18}$ Coverslips were mounted using ProLong Gold antifade reagent with DAPI (Invitrogen, Grand Island, NY) for nuclear staining. Antibodies are listed in Table 1.

\section{Dihydroethidium Staining}

Flash-frozen skin samples were cut at $5 \mu \mathrm{m}$ thickness and placed on type I collagen-coated coverslips (22 mm; BD, Franklin Lakes, NJ). These were mounted in Attofluor cell chambers (Invitrogen, Grand Island, NY) and incubated with $1 \mathrm{~mL}$ phosphate-buffered saline. The technical controls used a 5-minute pre-incubation with superoxide dismutase (SOD) $400 \mathrm{U} / \mathrm{mL}$ (Sigma-Aldrich, St. Louis, MO). Samples were stained with dihydroethidium (DHE) $(20 \mu \mathrm{mol} / \mathrm{L}$, Invitrogen) and imaged with laser confocal microscopy after 10 minutes. Excitation and emission wavelengths were 515 and $580 \mathrm{~nm}$, respectively.

\section{Immunoblot}

Flash-frozen tissues were stored in cryotubes at $-80^{\circ} \mathrm{C}$, homogenized (Kinematica, Newark, NJ) in radioimmunoprecipitation assay (RIPA) buffer (Thermo Scientific, Rockford, IL) with protease inhibitor cocktail (Sigma-Aldrich, St. Louis, MO), and centrifuged to remove debris. Proteins $(15 \mu \mathrm{g}$ ) were then separated using SDS-polyacrylamide gel electrophoresis with $4 \%$ to $20 \%$ gradient gels (Invitrogen, Grand Island, NY), transferred to nitrocellulose, blocked (5\% dry milk in Tris-buffered saline), and incubated with antibodies as indicated. Fibronectin
(1:3000) was obtained from Sigma; PDGF receptor $\beta, 958$ Nox4, and glyceraldehyde 3-phosphate dehydrogenase (GAPDH) were obtained from Santa Cruz Biotechnology (Santa Cruz, CA); and transforming growth factor (TGF) $-\beta 1$ and collagen IV were obtained from Abcam (Cambridge, MA). Antigen-antibody complexes were detected as described. ${ }^{19}$

\section{Quantitative Real-Time PCR}

Skin sections from animals were stored in RNALater stabilization reagent at $-80^{\circ} \mathrm{C}$, homogenized, and RNA extracted using TRizole (Invitrogen, Carlsbad, CA) according to the manufacturer's instructions. Using two control and two contrast-treated samples, cDNA was generated by reverse transcription (Applied Biosystems, Foster City, CA) from $0.5 \mu \mathrm{g}$ RNA (also according to the manufacturer's instructions). Quantitative RT-PCR amplification of the Nox1, Nox2 (Cybb), Nox4, actin (Actb), and GAPDH transcripts was conducted using Qiagen primers and SYBR Green PCR master mix (Applied Biosystems) with a RealPlex4 MasterCycler Epgradient S (Eppendorf, Westbury, NY) using RealPlex software. Relative gene expression was calculated using the $\Delta \Delta \mathrm{C}_{\mathrm{t}}$ method. ${ }^{20}$

\section{Results}

\section{Gross Findings, Weights, and Skin Thicknesses}

Animals were examined and weighed daily (Figure 2). Throughout the treatment period, there were no differences in weights between the saline- and contrasttreated groups $(P=0.5262)$, and gross skin findings were subtle. Of note, the contrast-treated animals universally demonstrated periorbital porphyrin staining within the third week. The thicknesses of midline dorsal skin did not differ between groups (Table 2).

\section{Dermal Morphology}

H\&E-stained and Masson's trichrome-stained skin demonstrated thickened epidermal layers, loss of dermal clefts, follicular epithelial cell hypertrophy, and hypercellularity in all of the contrast-treated animals (Figure 3A; see also Supplemental Table S1 at http://ajp.amjpathol. org). A dermatopathologist blinded to treatment was able to identify fibrosis and increased cellularity in $100 \%$ of the 


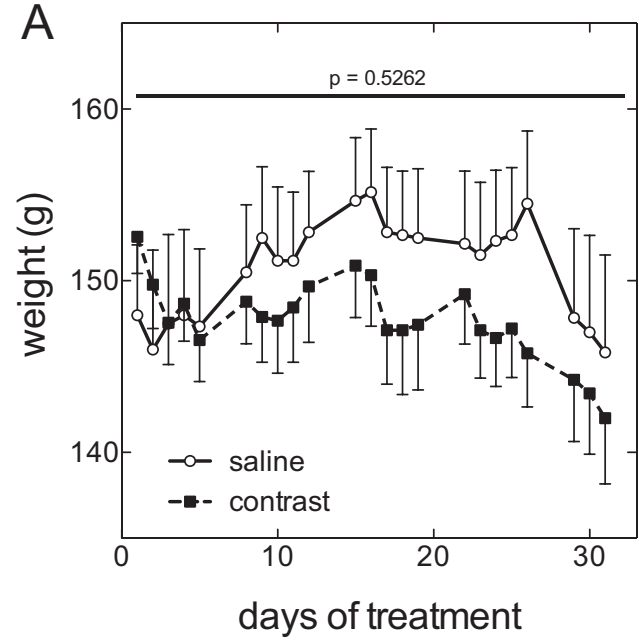

B

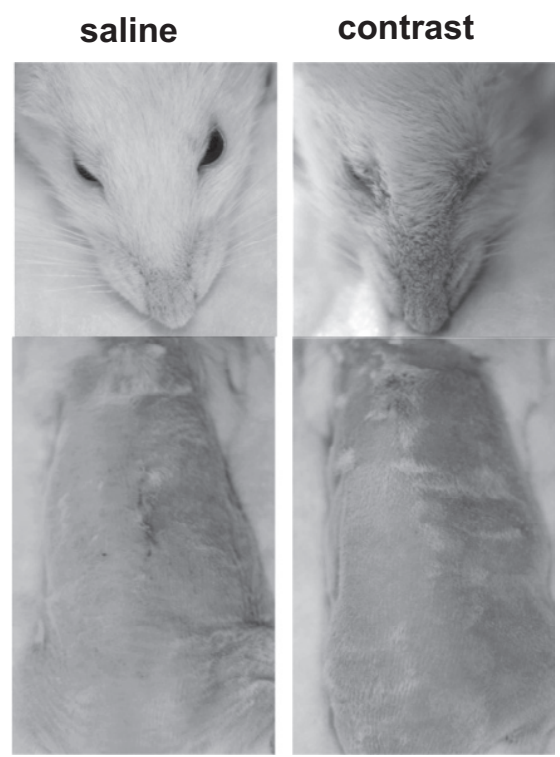

Figure 2. Weight trends and skin changes in saline- and contrast-treated rats. A: Mean weights for saline-treated $(n=6)$ and MRI contrast-treated $(n=9)$ animals. Values are mean \pm SEM. None of the values are significant using a two-way analysis of variance with Bonferroni post hoc analysis. B Few of the contrast-treated animals demonstrate any gross dermatological signs. Faces often demonstrate mild alopecia and periorbital porphyrin staining.

contrast-treated animals and none of the controls. Quantification of nuclei in the intermediate dermis demonstrated a fourfold increase in the contrast-treated group (Figure 3B).

\section{Dermal Myofibroblast Characteristics}

A defining feature of the activated myofibroblast is expression of $\alpha$-smooth muscle actin ( $\alpha \mathrm{SMA})$-containing stress fibers. Bone marrow-derived cells in the dermis of contrast-treated animals were characterized by a substantial positivity for $\alpha$ SMA (Figure 3C). TGF- $\beta$ and platelet-derived growth factor (PDGF) are central mediators in fibrotic disorders, ${ }^{21}$ and have been noted in NSF case reports $^{6}$ and implicated as a mediator using cultured dermal fibroblasts, ${ }^{22}$ respectively. Immunoblot of TGF- $\beta 1$ and PDGF receptor (PDGFR) $\beta$ in frozen skin demonstrated a significant increase of the former only (Figure 3D, left; see also Supplemental Figure S1 at http://ajp. amjpathol.org). Distribution of TGF- $\beta 1$ was throughout the dermis (Figure 3E). Fibronectin is synthesized by activated fibroblasts during granulation tissue formation and organ fibrosis. ${ }^{23-25}$ Bone marrow-derived cells and fibronectin (Fn-EIIIA isoform) were greatly increased in the contrast-treated group (Figure 3F). In contrast-treated animals, both hPAP and fibronectin were quantitatively greater as detected by immunoblot of homogenized skin (Figure 3G).

Activated myofibroblasts synthesize many components of extracellular matrix, including collagen type I. ${ }^{24}$ The dermis of contrast-treated animals demonstrated a denser pattern of type I collagen with respect to control, and this localized to the bone marrow-derived cells (Figure 4A). Collagen type IV is typically limited to the basement membrane of the epidermis, ${ }^{26}$ but this can be up-regulated in fibrosis, particularly by TGF- $\beta .^{27}$ The expression and distribution of collagen type IV in contrast-treated animals was increased in the papillary dermis (Figure 4B) and was matched by an increase in type IV collagen quantity (Figure 4C). Cathepsin $L$ is a lysosomal cysteine protease and is constitutively expressed in the dermis. This secreted proteinase contributes to balance and extracellular matrix turnover in skin homeostasis, ${ }^{28,29}$ and is a mediator of connective tissue remodeling. ${ }^{30}$ Hence, the expression of cathepsin $\mathrm{L}$ was investigated (Figure 4D). In contrast-treated animals, donor cells widely expressed cathepsin $L$ throughout the dermis, and the protein expression was greatly enhanced (Figure 4E). Collectively, these data demonstrate that contrast treatment leads to a definitive increase in dermal cellularity and fibrosis, with a significant proportion of $\alpha \mathrm{SMA}^{+}$bone marrow-derived cells.

Table 2. Effect of MRI Contrast on Skin Fold Thicknesses

\begin{tabular}{lccr}
\hline $\begin{array}{c}\text { Outcome } \\
\text { measure }(\mathrm{mm})\end{array}$ & \begin{tabular}{c} 
Bone marrow transplant \\
\cline { 3 - 3 }
\end{tabular} & Saline $(\mathrm{n}=7)$ & Contrast $(\mathrm{n}=8)$ \\
\hline Cervical & $1.9 \pm 0.2$ & $1.5 \pm 0.3$ & $1.6 \pm 0.4$ \\
only $(\mathrm{n}=4)$ & $1.5 \pm 0.5$ & $1.7 \pm 0.4$ \\
Lumbar & $1.8 \pm 0.3$ & $1.5 \pm 0.4$ & $1.6 \pm 0.3$ \\
\hline
\end{tabular}

\pm indicates mean \pm SD. There were no statistical differences between groups.

$\bar{P}$ values are for the comparison among all groups, one-way analysis of variance with a Tukey post hoc analysis. 
A

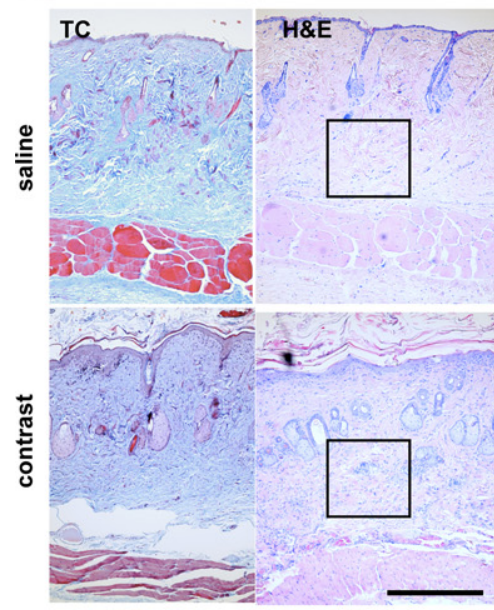

C

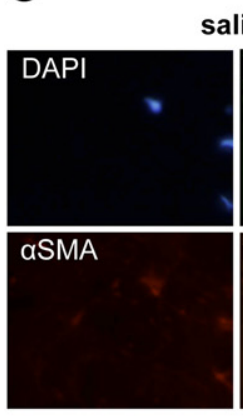

saline

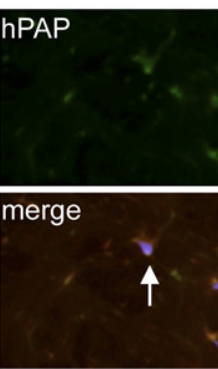

E

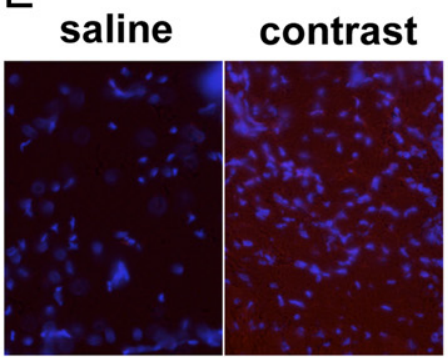

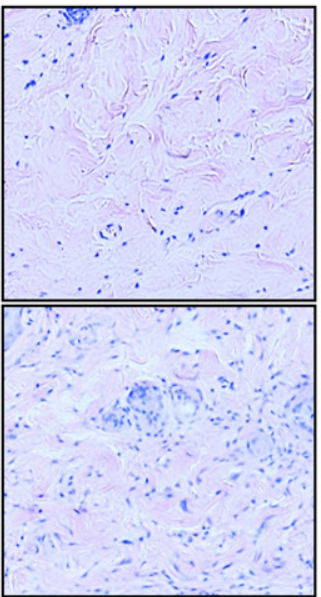
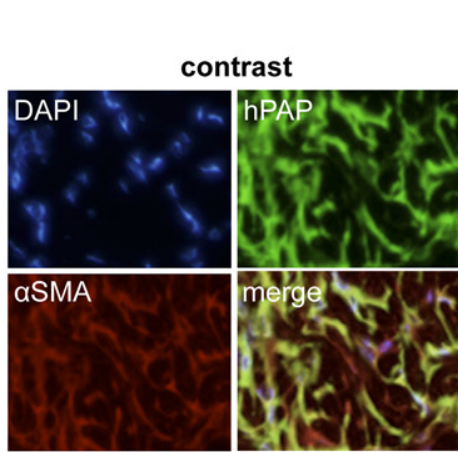

$\mathrm{F}$
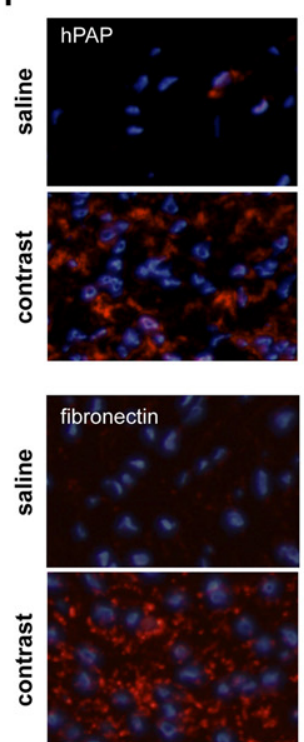

B

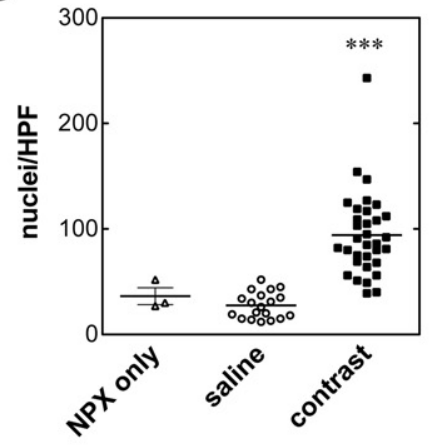

D contrast - - + +
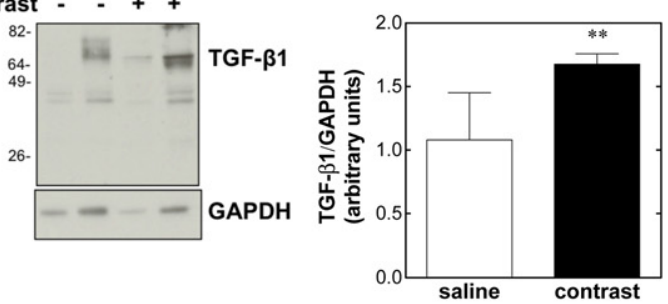

Figure 3. Skin changes in saline- and MRI contrast-treated rats. A: Skin from the contrast-treated group showed epidermal thickening, sebaceous cell hypertrophy, and increased dermal cellularity with respect to the saline-treated group (see Supplemental Table S1 at http://ajp.amjpathol.org). H\&E, hematoxylin and eosin; TC, Masson's trichrome. Scale bars $=500 \mu \mathrm{m}$. B: Contrast treatment increases dermal cellularity. Nuclei per high-power field were counted in the dermal regions in triplicate for the saline- and MRI contrast-treated animals. One group of age-matched animals status post $5 / 6$ nephrectomy (NPX) only (without lethal irradiation and bone marrow transplantation) was provided as a negative control. ${ }^{* * * *} P<0.001$ by two-tailed $t$-test with respect to the saline-treated group. C: Expression of the bone marrow marker, hPAP (fluorescein isothiocyanate secondary), and $\alpha$-smooth muscle actin ( $\alpha$ SMA, Cy3 secondary) in dermis. Nuclei are stained with DAPI. Arrow indicates a cell co-expressing both $\alpha$-SMA and the donor marker in the control Immunofluorescence, original magnification $\times 40$. D: Immunoblot for TGF- $\beta 1$ in rat skin. Quantification by pixel densitometry of antigens relative to loading controls (control $n=3$, contrast $n=4$ ). E: Expression of TGF- $\beta 1$ in rat skin from saline- and contrast-treated animals, respectively. Immunofluorescence, original magnification $\times 32$. F: Dermal expression of the bone marrow marker, hPAP (Cy3 secondary), and fibronectin (Cy3 secondary) in saline- and contrast-treated groups. Immunofluorescence, original magnification $\times 10)$. G: Expression of hPAP and fibronectin in rat skin. Immunofluorescence, original magnification $\times 10$. Quantification by pixel densitometry of antigens relative to loading controls $($ control $n=4$, contrast $n=5) .{ }^{* *} P<0.01$ by two-tailed $t$-test. 


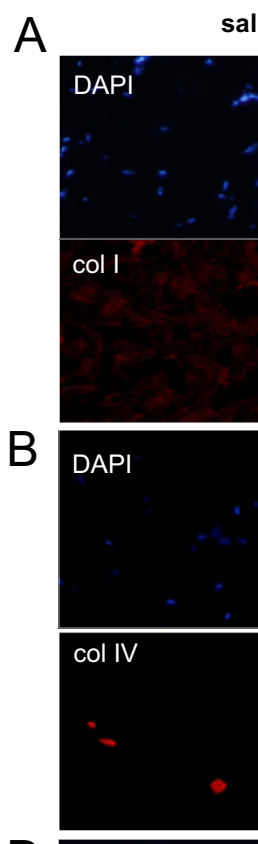

saline
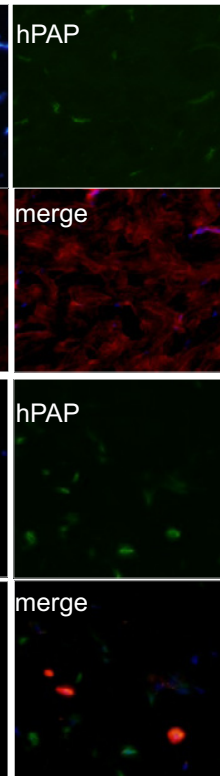

D DAPI
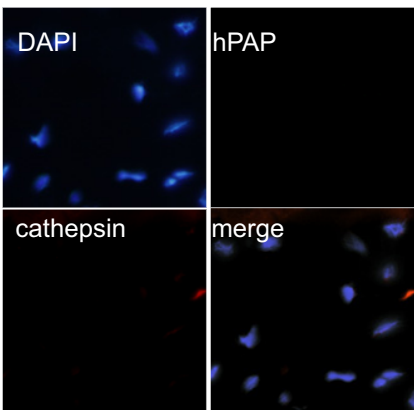

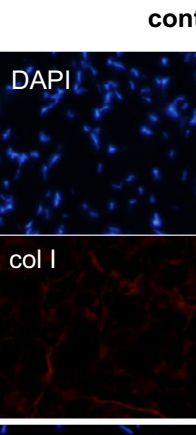

contrast

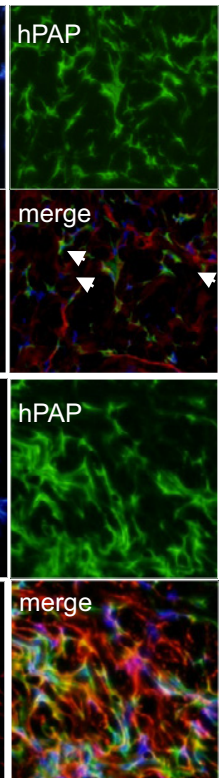

\section{C}
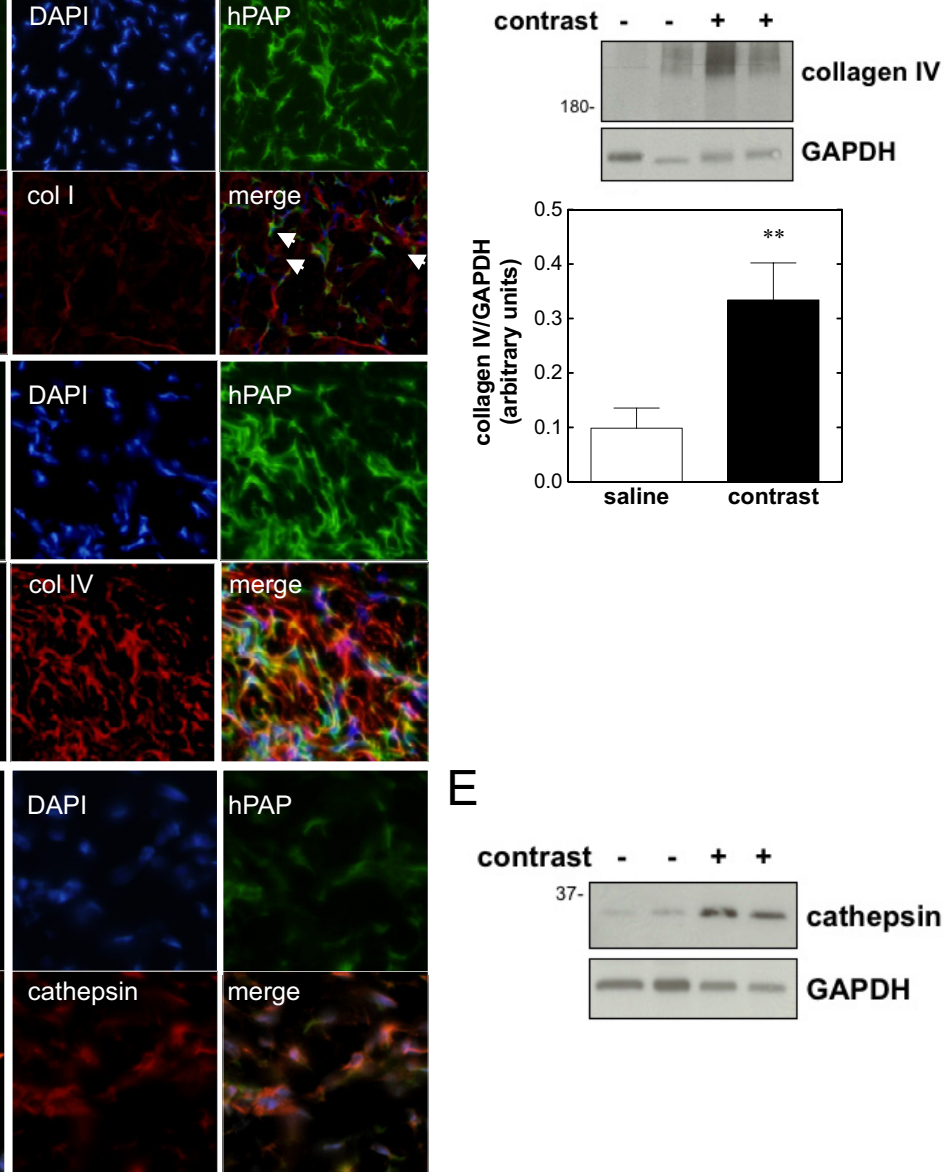

E

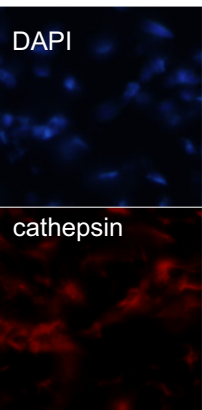

co

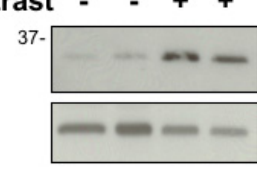

cathepsin L

GAPDH

Figure 4. Characterization of dermal extracellular matrix from saline- and contrast-treated animals. A: Expression of collagen (col) type I (Cy3 secondary) by bone marrow-derived cells in dermis. Immunofluorescence, original magnification $\times 20$. B: Expression of collagen type IV (Cy3 secondary) by bone marrow-derived cells in dermis. Immunofluorescence, original magnification $\times 20$. C: Immunoblot for collagen type IV in rat skins (control $n=4$, contrast $n=4$ ). ${ }^{* *} P<0.01$ using a two-tailed $t$-test.) D: Distribution of cathepsin L (Cy3 secondary) in dermis. Immunofluorescence, original magnification $\times 32$. E: Protein expression of cathepsin $\mathrm{L}$ in skin. Immunoblot.

\section{Dermal CD34 and Pro-Collagen I Expression}

The expression of CD34 and procollagen type I in NSF lesions suggests that MRI contrast-induced fibrosis is fibrocyte mediated. Therefore, CD34 and pro-collagen expression were examined relative to hPAP in frozen skin sections. The dermis from control animals did exhibit CD34 positivity, but this was markedly increased in the contrast-treated group (Figure 5A). Multinucleated giant cells have been reported in the skin from patients with $\mathrm{NSF}^{3,5,31}$ and in animals treated with gadolinium. ${ }^{32}$ In the contrast-treated animals, giant cells expressed CD34 as well. Similarly, perinuclear expression of procollagen I was scant in the control dermal cells, yet was often expressed in conjunction with the donor marker (Figure 5B). Stellate-shaped procollagen $\mathrm{I}^{+} / \mathrm{hPAP}^{+}$cells, in contrast, were markedly present in the skin of contrast-treated animals. Case reports of advanced NSF are notable for thickening of collagen bundles and an increased intensity of procollagen I expression. ${ }^{3}$ Procollagen I was substantially increased and confined to donor cells in the dermis of the contrast-treated group. These results sug- gest that in NSF, procollagen I- and CD34-expressing cellular lesions are indeed composed from a circulating, bone marrow-derived pool.

\section{Dermal Clotting Factor XIIIa and CD68 Expression}

Occasionally, cells of the monocyte-macrophage lineage that express factor XIIIa ${ }^{6,33,34}$ and $\mathrm{CD}^{3} 8^{3,35}$ can be present in NSF skin; therefore the presence of these was characterized. Stellate-shaped factor $\mathrm{XIII}^{+} / \mathrm{hPAP}^{+}$cells were much more prevalent in the dermis of the contrasttreated animals (Figure 6A). Many cells of host and donor origin were $\mathrm{CD}^{+} 8^{+}$, with a slight increase in the contrasttreated animals (Figure 6B). These data demonstrate that there are bone marrow-derived dendritic cells and macrophages present in the skin, and these are increased by $\mathrm{MRI}$ contrast treatment, but $\mathrm{CD}^{+} 8^{+}$cells do not comprise the majority of the overall tissue composition. 


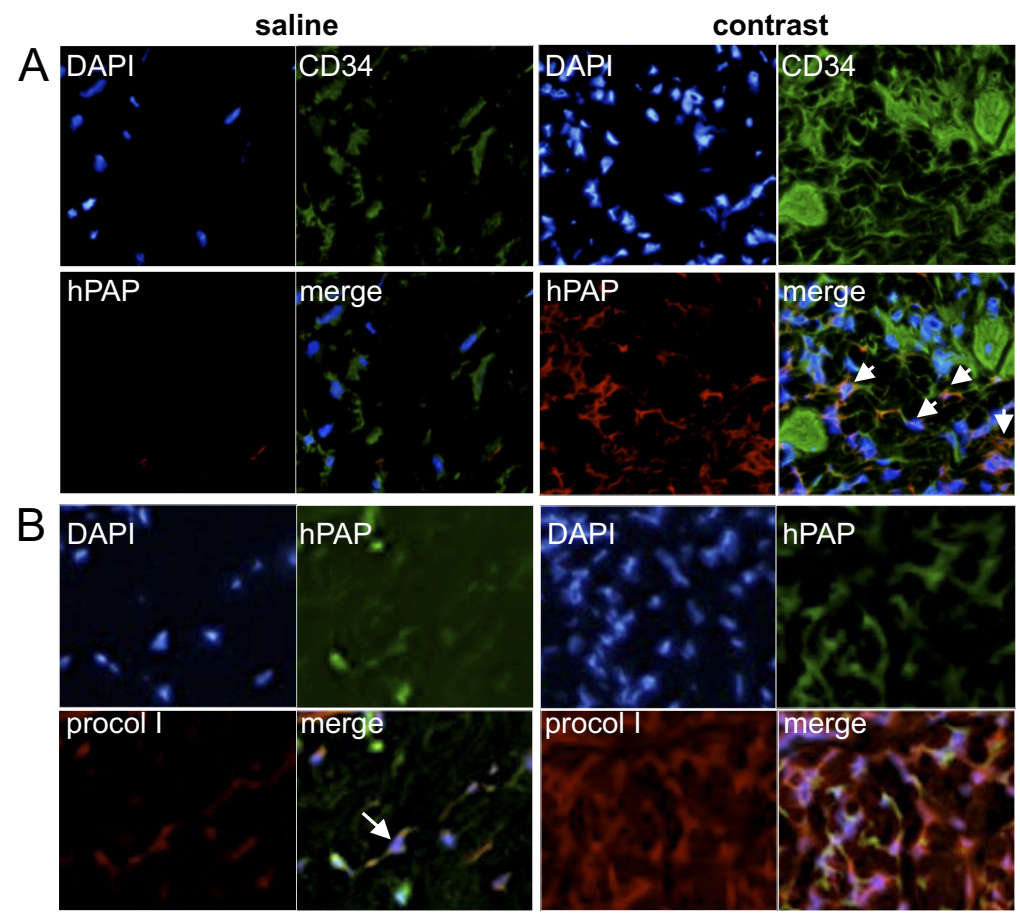

Figure 5. Characterization of bone marrow-derived cells in the dermis of contrast-treated animals. A: Expression of CD34 (fluorescein isothiocyanate secondary) by bone marrow-derived cells in dermis. Arrows indicate bone marrow-derived cells (hPAP is stained with Cy3) that express CD34. Immunofluorescence, original magnification $\times 32$. B: Expression of procollagen (procol) type I (Cy3 secondary) by bone marrowderived cells in dermis. Immunofluorescence, original magnification $\times 20$

\section{Reactive Oxygen Species Involvement in Dermal Fibrosis}

Despite the known role of reactive oxygen species in fibrosis, ${ }^{11}$ very little has been reported with respect to NSF. Frozen skin sections were stained with a superoxide-specific marker, DHE, and imaged by laser scanning confocal microscope (Figure 7A). Staining was increased in skin from contrast-treated animals. Preincubation of the skin with SOD quenched the DHE signal. Several homologs of the $\mathrm{NAD}(\mathrm{P}) \mathrm{H}$ oxidases and the phagocytic oxidase (phox) proteins have been detected in skin. ${ }^{36}$ Therefore, the quantity of the $\mathrm{NAD}(\mathrm{P}) \mathrm{H}$ oxidase homologs Nox1, gp9 $1^{\text {phox }}$, Nox3, and Nox4 saline

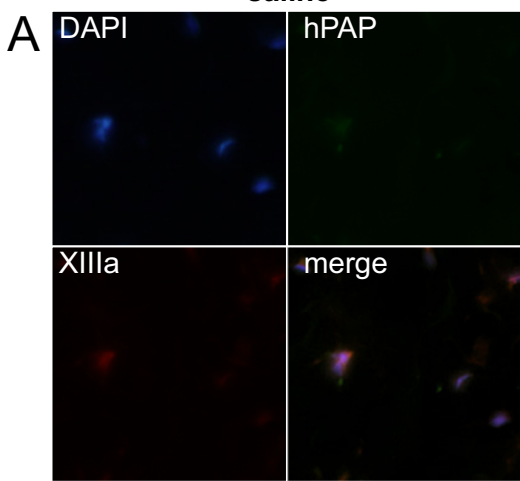

B

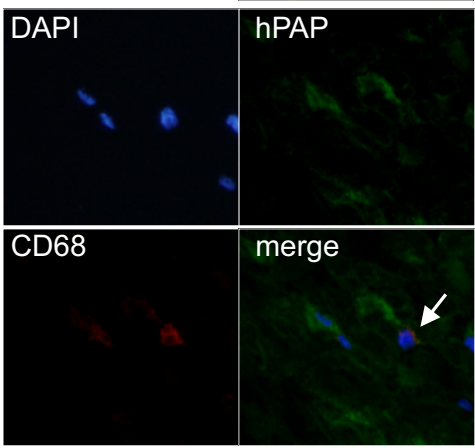

contrast
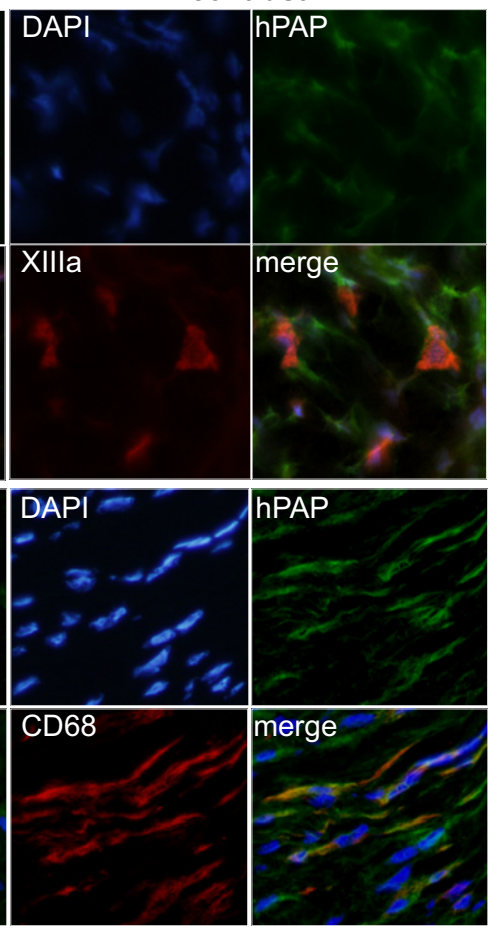

Figure 6. Factor XIIIa and CD68 expression in the dermis of contrast-treated animals. A: Dermal clotting factor XIIIa is increased in the dermis of contrast-treated animals. B: CD68 expression in control and contrast-treated rat skin. Arrow depicts a bone marrow-derived cell that co-expressed CD68 (Cy3 secondary) in the control tissue. Immunofluorescence, original magnification $\times 32$ 

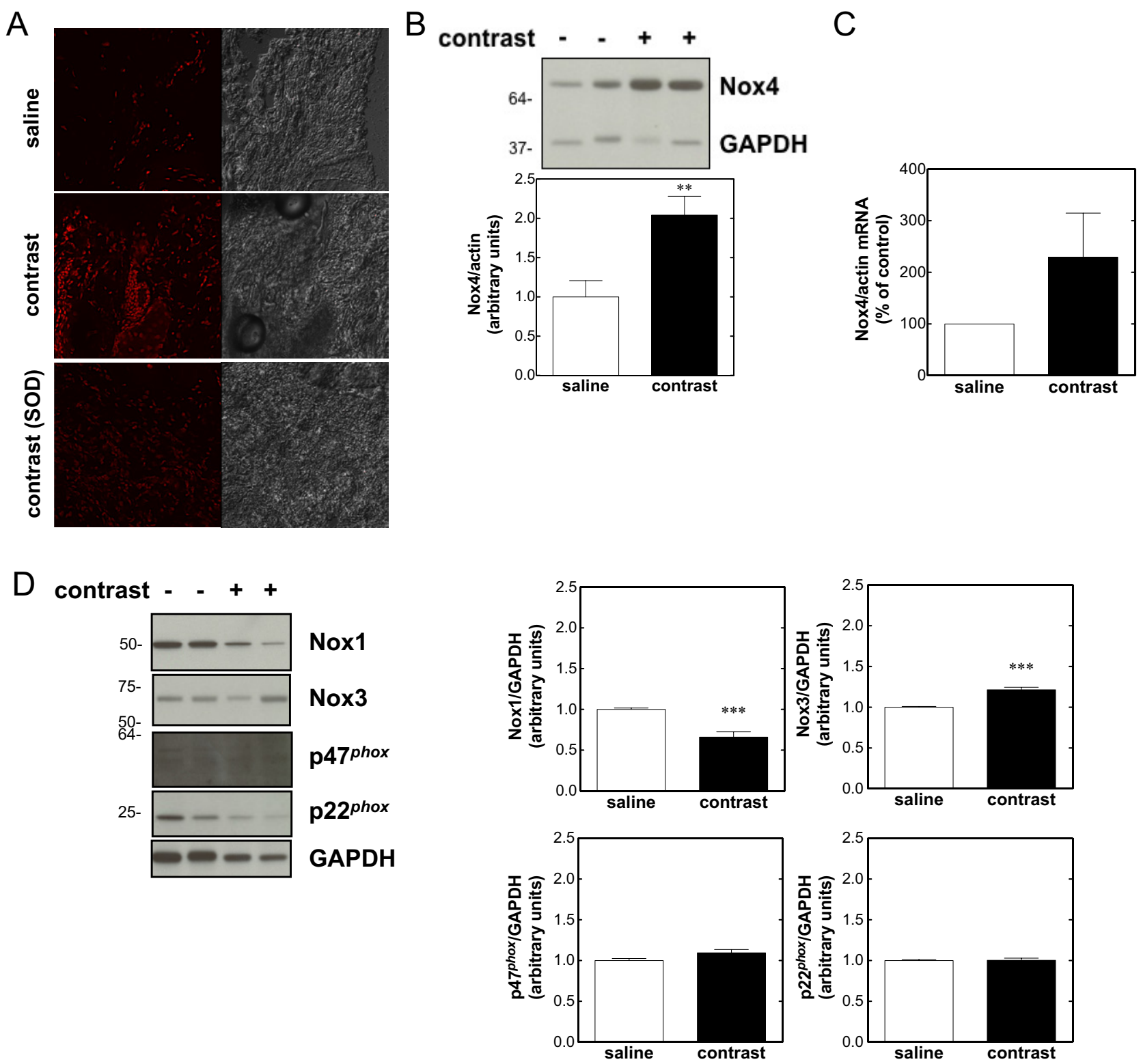

Figure 7. Oxidative stress in the skin of contrast-treated animals. A: Dihydroethidium (DHE)-stained, frozen skin sections (left panels); the right panels are the corresponding light-microscopic photographs. One skin section from a contrast-treated animal was incubated with superoxide dismutase (SOD, $400 \mathrm{U} / \mathrm{mL}$ ) to demonstrate the specificity of DHE staining. Confocal, original magnification $\times 200$. B: Immunoblot for Nox 4 in skin from control and contrast-treated animals. C: Relative mRNA transcripts in skin from quantitative real-time PCR for Nox4 on control and contrast-treated animals. D: Immunoblot for Nox1, Nox3, p47phox, and p22phox in skin from control and contrast-treated animals. Barograms illustrate a quantification of the intensity of the bands measured by pixel densitometry relative to GAPDH, the loading control.

and the $\mathrm{NAD}(\mathrm{P}) \mathrm{H}$ oxidase subunits $\mathrm{p} 47^{\text {phox }}$ and p22 $2^{\text {phox }}$ were examined by immunoblot (Figure $7, \mathrm{~B}$ and D). In skin, gp91 ${ }^{\text {phox }}$ was undetectable (data not shown). The increase in superoxide production correlated with an increase in $\mathrm{NAD}(\mathrm{P}) \mathrm{H}$ oxidase Nox4 (Figure 7B). Quantitative RT PCR for Nox1, Nox2, and Nox4 was conducted. The largest increase in mRNA relative to the housekeeping gene actin was for Nox4 (Figure 7C). These observations are of importance because Nox4 has been identified to mediate fibrotic processes in various diseases, ${ }^{15,37}$ and Nox4-derived reactive oxygen species (ROS) have been detected in stimulated dermal fibroblasts. ${ }^{38}$

\section{Cardiac and Liver Morphology}

Widespread, systemic fibrosis is associated with the disease; therefore, heart and liver were examined. Histological specimens failed to identify differences in fibrosis among control and contrast-treated animals in the left cardiac ventricle (Figure 8A). After the administration of gadolinium-based contrast, relatively high concentrations are found in the liver even weeks after the exposure in animals with normal renal function. ${ }^{39-41}$ There were no signs of liver fibrosis in either group (Figure 8A). Immunofluorescence of frozen ventricle and liver specimens (Figure 8B) demonstrated no difference in CD34 expres- 
A

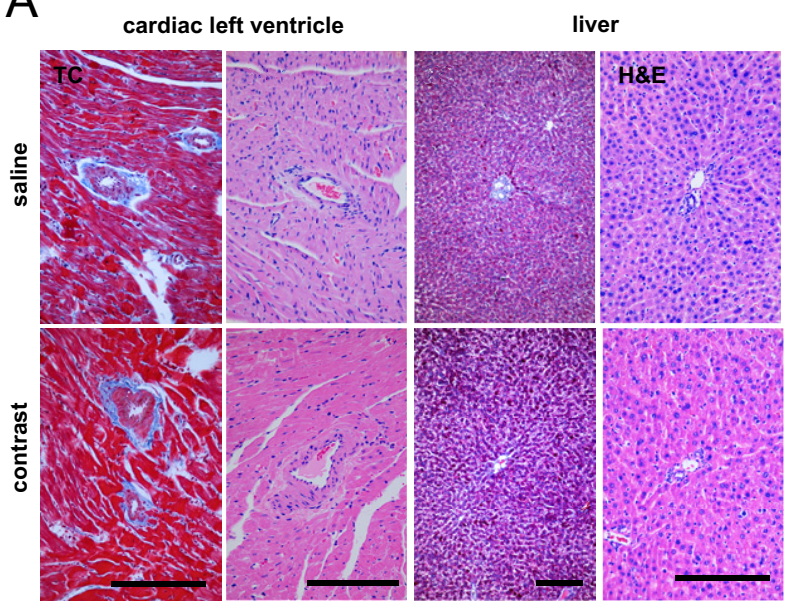

$\mathrm{B}$
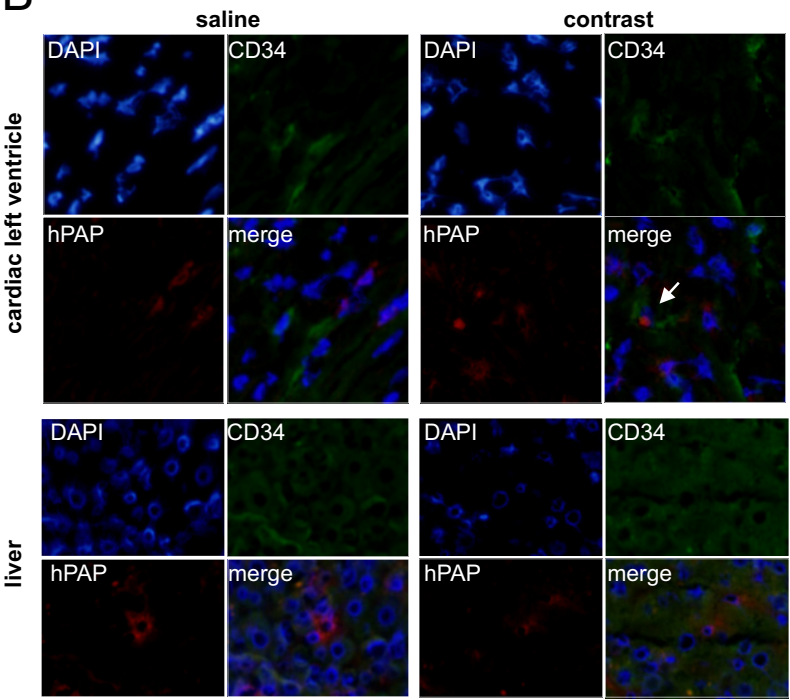

CD34

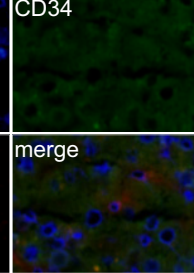

C

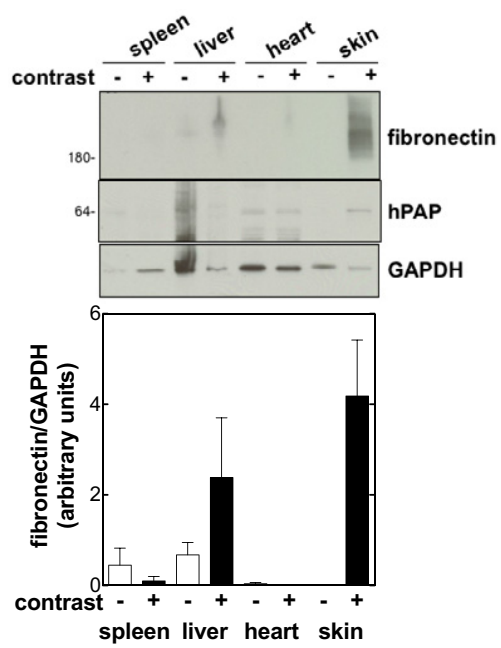

Figure 8. Organ-specific changes in contrast-treated animals. A: Left cardiac ventricle and liver histology. Scale bars $=200 \mu \mathrm{m}$. B: Localization of hPAP and CD34 in the left ventricle and liver. The arrow indicates a bone marrowderived cell expressing CD34 in the left ventricle from a contrast-treated animal. Immunofluorescence, original magnifications $\times 32$ (heart) and $\times 16$ (liver). C: Immunoblot for fibronectin and hPAP in control and contrasttreated animals. sion or hPAP. When comparing fibronectin and the bone marrow marker hPAP among spleen, liver, heart, and skin samples, the most significant increases were in the skin and liver (Figure 8C). In total, these data indicate that skin is the primary organ to be affected by infiltration of circulating fibrocytes with concomitant fibrosis and suggest that liver involvement may follow.

In skin, these data suggest that reactive oxygen species mediate pathological processes in MRI contrastinduced fibrosis. Tempol is a radical scavenger that acts as a SOD mimetic. ${ }^{42}$ The effect of administration of tempol on skin pathology in MRI contrast-treated rats with 5/6 nephrectomy was examined (Figure 9). Female Fischer 344 rats were randomized to control, MRI contrast $(2.5 \mathrm{mmol} / \mathrm{kg}, \mathrm{IP})$, or MRI contrast with tempol $(1 \mathrm{mmol} / \mathrm{L}$ in the drinking water) groups. This study was performed for 3 weeks. Dermis from animals in the MRI contrast co-treated with tempol demonstrated markedly less cellularity than that from animals contrast-treated only (Figure 9, A and B). Although fibronectin was markedly increased in skin from contrast-treated animals, this was abrogated by tempol treatment (Figure 9C). In addition, tempol treatment decreased CD34 and $\alpha$ SMA expression in the dermis (Figure 9D). Skin from animals in the MRI contrast/tempol co-treatment group demonstrated markedly less DHE staining than that in the MRI contrast-only group (Figure 9E). These data indicate that ROS mediate pathological processes in MRI contrast-induced skin fibrosis, and that the SOD mimetic tempol abrogates this effect.

\section{Discussion}

The lesions of nephrogenic systemic fibrosis may develop rapidly and are symmetric, hypercellular, and characterized by intense CD34 and procollagen expression. There is an absence of mitotic nuclei among the spindle cells. Because of the similarity to wound healing, these features have led to the supposition that a circulating factor or cell mediates the disease. ${ }^{10}$ However, the cell fraction of $\mathrm{CD}_{3}{ }^{+}$bone marrow-derived cells ranges from multipotent hematopoietic progenitors, to precursors of thrombocytes, myeloid and lymphoid cells, mast cells, and vascular endothelium. ${ }^{13}$ This marker is also expressed in the reticular dermis by interstitial and perivascular spindle-shaped and dendritic cells, and in the spindle cells peripheral to the eccrine sweat glands, ${ }^{43,44}$ and adult vascular endothelium. ${ }^{13,45}$ Therefore, although CD34 and procollagen type I are major antigens for characterizing fibrocytes ${ }^{46}$ and although these markers are clearly associated with NSF, ${ }^{47}$ until now there have been no prospective experiments demonstrating a circulating bone marrow-derived cell as a principal mediator of the disease.

In this study, a novel animal model for the study of MRI contrast-induced systemic fibrosis was established. Animals tolerated 5/6 nephrectomy, lethal irradiation, and salvage bone marrow transplantation, and treatment with high doses of MRI contrast very well. Of interest was the development of chromodacryorrhea (periorbital porphy- 
A

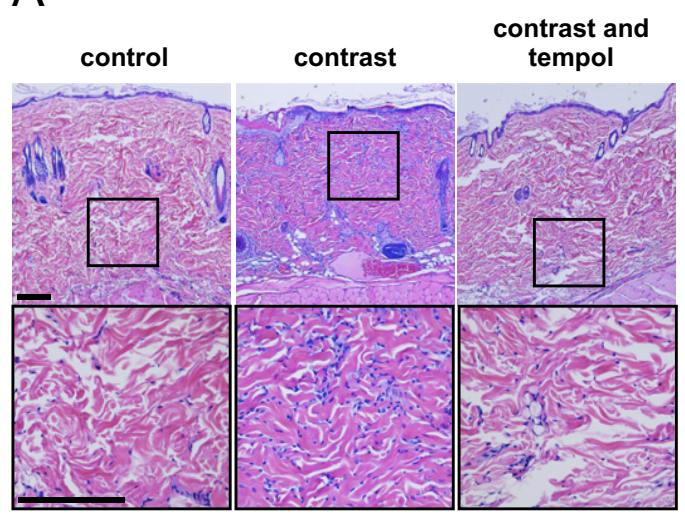

D

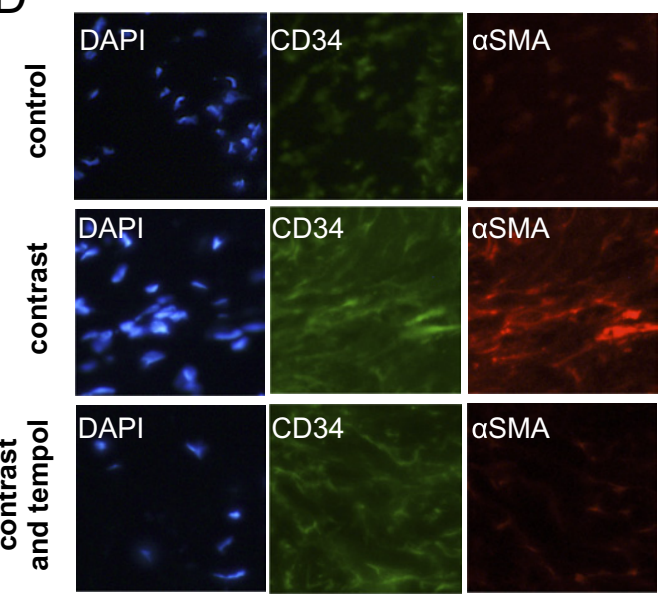

B

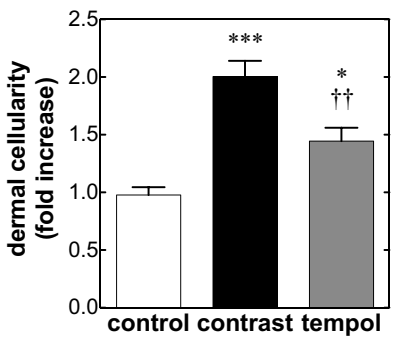

C

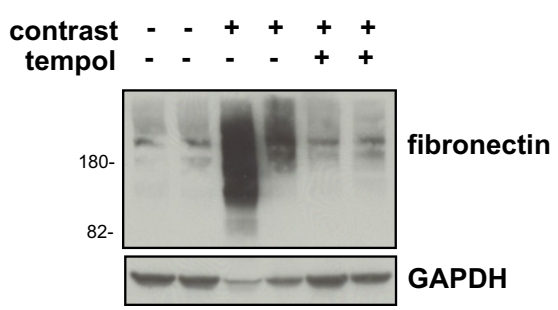

$E$
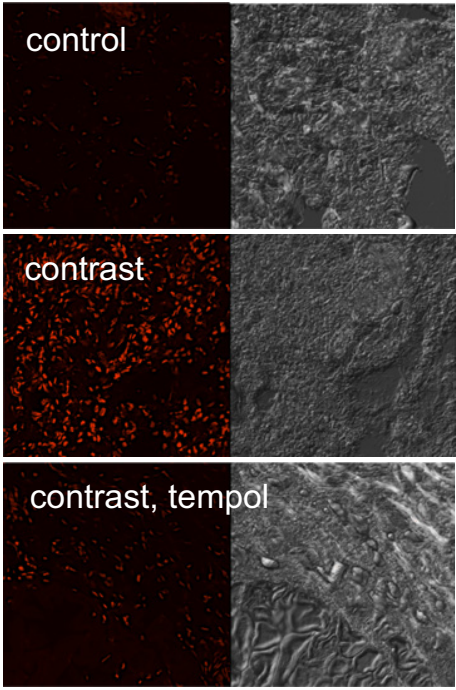

contrast (SOD)

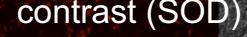

Figure 9. Skin from rats treated with the superoxide dismutase mimetic, tempol, demonstrate reduced fibrosis, reduced dermal cellularity, and reduced oxidative stress. A: Rats with 5/6 nephrectomy were randomized to control $(n=4)$, MRI contrast $(n=4)$, or MRI contrast with tempol $(1$ mmol/L) in the drinking water ad libitum $(n=4)$. Animals were sacrificed after 3 weeks of treatment. H\&E, scale bar $=200 \mu \mathrm{m}$. B: Tempol treatment inhibits MRI contrast-induced cellularity in dermis. ${ }^{* * *} P<0.001$ and ${ }^{*} P<0.05$ by one-way analysis of variance and Tukey post boc analysis with respect to the saline-treated group. ${ }^{+t} P<0.01$ versus MRI contrast-treated group. C: Tempol treatment reduces fibronectin accumulation in rat skin. Immunoblot. D: Tempol treatment attenuates $\alpha$ SMA and CD34 expression in the dermis of MRI contrast-treated animals. Immunofluorescence, original magnification $\times 32$. E: Tempol treatment reduced DHE staining in skin from MRI contrast-treated animals. One skin section from a contrast-treated animal was incubated with SOD ( $400 \mathrm{U} / \mathrm{mL}$ ) to demonstrate the specificity of DHE staining. Confocal, original magnification $\times 200$.

rin staining) in $100 \%$ of the gadodiamide-treated animals. The dermal pathology resembles the human disease identically in the magnitude of dermal cellularity and the presence of several markers of fibrosis (fibronectin, collagen types I and IV, and TGF- $\beta$ ). A fourfold increase in dermal cellularity is on par with that found by others. ${ }^{16}$ Remarkably, the dermal cellularity as expressed per high-power field is of the same magnitude found in NSF biopsy specimens largely from end-stage renal disease patients exposed to gadopentetate. ${ }^{48}$ What differentiates our model from prior studies is that a $5 / 6$ nephrectomy to induce renal insufficiency was used and transplanted
hPAP-expressing bone marrow afforded identification of the origin of cells in each organ.

Consistent with the human disorder, there were increases in dermal CD34, procollagen I, $\alpha$-SMA, and cellularity. The markers co-localized with markers of fibrosis, the proteinase cathepsin $\mathrm{L}$, and the bone marrow tag. Up to this point, the origin of dermal hypercellularity has been assumed to be from a circulating pool, but this was based on observational data alone. Our work provides substantial, experimental evidence that that the cellular mediators are indeed bone marrow derived. Furthermore, we demonstrate that MRI contrast-induced fibrosis ini- 
tially involves the skin. There were hardly any aberrancies in left cardiac ventricle or liver. These negative findings may be due to the single time point studied and/or that the animals modeled an impairment of glomerular filtration rate rather than dialysis-dependent end-stage renal disease.

Reports on prior rodent models of NSF have been published, but these have been mostly in animals without CKD, and some have had conflicting results. ${ }^{16,49}$ Our model adds to the existing evidence in the characterization of the markers of fibrosis, the demonstration of CD34 and procollagen I in the dermis, identification of TGF- $\beta 1$, ROS, and Nox4 in fibrotic skin. Unique to this study is that all of these markers are now linked to circulating, bone marrow-derived cells. Co-localization of CD34 and procollagen I to bone marrow-derived cells proves that circulating fibrocytes are involved. However, it is notable that there was an increased expression of CD34 by the host cells as well; therefore, using this marker as evidence for involvement of a circulating, hematopoieticderived cell in fibrotic disorders should be done with caution.

Mild CD68 expression in dermis parallels that found in the human disorder. Interestingly, although the fibroblast chemoattractant platelet-derived growth factor (PDGF) and its receptors (PDGFR) are increased in a multitude of fibrotic diseases, including wound healing, ${ }^{50}$ and PDGFR activation has been implicated in gadolinium-induced fibrosis,, ${ }^{22}$ PDGFR $\beta$ expression was clearly not increased in the skin using our model. This may indicate a different mechanism of MRI contrast-induced fibrosis as opposed to gadolinium chloride, that ionic gadolinium has a compound effect on dermal fibroblasts and fibrocytes, or that the PDGFR may not be involved in the process of MRI contrast-induced fibrosis in vivo.

The prevailing model of nephrogenic systemic fibrosis is that poor elimination of MRI contrast in patients with renal insufficiency leads to tissue retention of the agents. Ionic gadolinium is eventually liberated from the chelates, the metal deposits in tissues, and this process leads to the recruitment and activation of circulating fibrocytes. Our data lend support to the concept of a fibrocytemediated process. Co-localization studies for fibronectin and collagen IV indicate that these bone marrow-derived cells are mediators. The work provides experimental proof that bone marrow-derived cells are indeed involved in the dermal fibrosis. This conclusion is based on i) the experimental design, ii) co-localization of the bone marrow-derived cells with markers of fibrosis, and iii) the significant increase in dermal cellularity (much of which was $\mathrm{hPAP}^{+}$) in the contrast-treated animals.

We are not aware of any publications that have identified the generation of ROS in the pathophysiology of NSF. Not only has this been demonstrated by our study, but this increased oxidative stress is associated with an increase in Nox4, implying that Nox4 is an important source of these ROS in disease, as it is in other maladies. ${ }^{15}$ Nox4 has been implicated in another disorder, idiopathic pulmonary fibrosis, ${ }^{51}$ which is largely thought to be fibrocyte mediated. In accordance with our study, TGF- $\beta 1$ increased Nox4 in pulmonary mesenchymal cells, and this culminated in myofibroblast proliferation and extracellular matrix generation. ${ }^{52}$ Similarly, Nox4 has been identified as a mediator for TGF- $\beta 1$-induced fibroblast activation and fibronectin generation in kidney. ${ }^{53}$ Angiotensin II induces mesangial cell fibronectin generation in the same Nox4 dependent manner. ${ }^{54}$

In conclusion, we have developed a model of MRI contrast-induced fibrosis using rats with renal insufficiency and status post lethal irradiation and salvage bone marrow transplantation that identified the composition of cells in affected lesions. Circulating, bone marrow-derived cells are increased in the dermis of treated animals and are associated with increased expression of fibrotic markers, oxidative stress, and Nox4. The model lends itself not only to mechanistic investigation, but also for testing potential therapies.

\section{Acknowledgments}

We thank Duck Y. Lee for his expertise and contribution to the DHE experiments.

\section{References}

1. Daram SR, Cortese CM, Bastani B: Nephrogenic fibrosing dermopathy/nephrogenic systemic fibrosis: report of a new case with literature review. Am J Kidney Dis 2005, 46:754-759

2. Cowper SE, Rabach M, Girardi M: Clinical and histological findings in nephrogenic systemic fibrosis. Eur J Radiol 2008, 66:191-199

3. Cowper SE, Su LD, Bhawan J, Robin HS, LeBoit PE: Nephrogenic fibrosing dermopathy. Am J Dermatopathol 2001, 23:383-393

4. Knopp EA, Cowper SE: Nephrogenic systemic fibrosis: early recognition and treatment. Semin Dial 2008, 21:123-128

5. Koreishi AF, Nazarian RM, Saenz AJ, Klepeis VE, McDonald AG Farris AB, Colvin RB, Duncan LM, Mandal RV, Kay J: Nephrogenic systemic fibrosis: a pathologic study of autopsy cases. Arch Pathol Lab Med 2009, 133:1943-1948

6. Jimenez SA, Artlett CM, Sandorfi N, Derk C, Latinis K, Sawaya H, Haddad R, Shanahan JC: Dialysis-associated systemic fibrosis (nephrogenic fibrosing dermopathy): study of inflammatory cells and transforming growth factor beta1 expression in affected skin. Arthritis Rheum 2004, 50:2660-2666

7. Ting WW, Stone MS, Madison KC, Kurtz K: Nephrogenic fibrosing dermopathy with systemic involvement. Arch Dermatol 2003, 139: 903-906

8. Anonymous: Questions and answers on gadolinium-based contrast agents. United States Food and Drug Administration. Center for Drug Evaluation and Research, 2007

9. Quan TE, Cowper S, Wu SP, Bockenstedt LK, Bucala R: Circulating fibrocytes: collagen-secreting cells of the peripheral blood. Int J Biochem Cell Biol 2004, 36:598-606

10. Cowper SE, Bucala R: Nephrogenic fibrosing dermopathy: suspect identified, motive unclear. Am J Dermatopathol 2003, 25:358

11. Mori L, Bellini A, Stacey MA, Schmidt M, Mattoli S: Fibrocytes contribute to the myofibroblast population in wounded skin and originate from the bone marrow. Exp Cell Res 2005, 304:81-90

12. Border WA, Ruoslahti E: Transforming growth factor-beta in disease: the dark side of tissue repair. J Clin Invest 1992, 90:1-7

13. Furness SG, McNagny K: Beyond mere markers: functions for CD34 family of sialomucins in hematopoiesis. Immunol Res 2006, 34:13-32

14. Odorfer KI, Unger NJ, Weber K, Sandgren EP, Erben RG: Marker tolerant, immunocompetent animals as a new tool for regenerative medicine and long-term cell tracking. BMC Biotechnol 2007, 7:30-38

15. Barnes JL, Gorin Y: Myofibroblast differentiation during fibrosis: role of NAD(P)H oxidases. Kidney Int 2011, 79:944-956

16. Sieber MA, Pietsch H, Walter J, Haider W, Frenzel T, Weinmann HJ: A preclinical study to investigate the development of nephrogenic 
systemic fibrosis: a possible role for gadolinium-based contrast media. Invest Radiol 2008, 43:65-75

17. Kisseberth WC, Brettingen NT, Lohse JK, Sandgren EP: Ubiquitous expression of marker transgenes in mice and rats. Dev Biol 1999 214:128-138

18. Faulkner JL, Szcykalski LM, Springer F, Barnes JL: Origin of interstitial fibroblasts in an accelerated model of angiotensin II-induced rena fibrosis. Am J Pathol 2005, 167:1193-1205

19. Ricono JM, Wagner B, Gorin Y, Arar M, Kazlauskas A, Choudhury GG, Abboud HE: PDGF receptor- $\beta$ modulates metanephric mesenchyme chemotaxis induced by PDGF AA. Am J Physiol Renal Physiol 2009, 296:F406-F417

20. Eid AA, Gorin Y, Fagg BM, Maalouf R, Barnes JL, Block K, Abboud $\mathrm{HE}$ : Mechanisms of podocyte injury in diabetes: role of cytochrome P450 and NADPH oxidases. Diabetes 2009, 58:1201-1211

21. Bonner JC: Regulation of PDGF and its receptors in fibrotic diseases. Cytokine Growth Factor Rev 2004, 15:255-273

22. Bhagavathula N, Dame MK, DaSilva M, Jenkins W, Aslam MN, Perone P, Varani J: Fibroblast response to gadolinium: role for plateletderived growth factor receptor. Invest Radiol 2010, 45:769-777

23. Serini G, Bochaton-Piallat ML, Ropraz P, Geinoz A, Borsi L, Zardi L, Gabbiani G: The fibronectin domain ED-A is crucial for myofibroblastic phenotype induction by transforming growth factor-beta1. J Cell Biol 1998, 142:873-881

24. Sorrell JM, Caplan Al: Fibroblasts-a diverse population at the center of it all. Int Rev Cell Mol Biol 2009, 276:161-214

25. Barnes VL, Musa J, Mitchell RJ, Barnes JL: Expression of embryonic fibronectin isoform EIIIA parallels alpha-smooth muscle actin in maturing and diseased kidney. J Histochem Cytochem 1999, 47:787798

26. Yoshioka K, Hino S, Takemura T, Maki S, Wieslander J, Takekoshi Y Makino H, Kagawa M, Sado Y, Kashtan CE: Type IV collagen alpha 5 chain. Normal distribution and abnormalities in X-linked Alport syndrome revealed by monoclonal antibody, Am J Pathol 1994, 144: 986-996

27. Grassel S, Unsold C, Schacke H, Bruckner-Tuderman L, Bruckner P Collagen $\mathrm{XVI}$ is expressed by human dermal fibroblasts and keratinocytes and is associated with the microfibrillar apparatus in the upper papillary dermis. Matrix Biol 1999, 18:309-317

28. Bylaite M, Moussali H, Marciukaitiene I, Ruzicka T, Walz M: Expression of cathepsin $L$ and its inhibitor hurpin in inflammatory and neoplastic skin diseases. Exp Dermatol 2006, 15:110-118

29. Walz M, Kellermann S, Bylaite M, Andree B, Ruther U, Paus R, Kloepper JE, Reifenberger J, Ruzicka T: Expression of the human Cathepsin L inhibitor hurpin in mice: skin alterations and increased carcinogenesis. Exp Dermatol 2007, 16:715-723

30. Provenzano PP, Alejandro-Osorio AL, Valhmu WB, Jensen KT, Vanderby $R$, Jr.: Intrinsic fibroblast-mediated remodeling of damaged collagenous matrices in vivo. Matrix Biol 2005, 23:543-555

31. Kay J, Bazari H, Avery LL, Koreishi AF: Case records of the Massachusetts General Hospital. Case 6-2008. A 46-year-old woman with renal failure and stiffness of the joints and skin, N Engl J Med 2008, 358:827-838

32. Abraham JL, Thakral C: Tissue distribution and kinetics of gadolinium and nephrogenic systemic fibrosis. Eur J Radiol 2008, 66:200-207

33. Ortonne N, Lipsker D, Chantrel F, Boehm N, Grosshans E, Cribier B: Presence of CD45RO + CD34+ cells with collagen synthesis activity in nephrogenic fibrosing dermopathy: a new pathogenic hypothesis. Br J Dermatol 2004, 150:1050-1052

34. Quatresooz P, Paquet P, Hermanns-Le T, Pierard GE: Immunohistochemical aspects of the fibrogenic pathway in nephrogenic systemic fibrosis. Appl Immunohistochem Mol Morphol 2010, 18:448-452

35. Kay J, Czirjak L: Gadolinium and systemic fibrosis: guilt by association. Ann Rheum Dis 2010, 69:1895-1897
36. Chamulitrat W, Stremmel W, Kawahara T, Rokutan K, Fujii H, Wingler K, Schmidt HH, Schmidt R: A constitutive NADPH oxidase-like system containing gp91phox homologs in human keratinocytes. J Invest Dermatol 2004, 122:1000-1009

37. Gorin Y, Block K, Hernandez J, Bhandari B, Wagner B, Barnes JL, Abboud HE: Nox4 NAD(P)H oxidase mediates hypertrophy and fibronectin expression in the diabetic kidney. J Biol Chem 2005, 280 : 39616-39626

38. Rossary A, Arab K, Steghens JP: Polyunsaturated fatty acids modulate NOX 4 anion superoxide production in human fibroblasts, Biochem J 2007, 406:77-83

39. Pietsch H, Jost G, Frenzel T, Raschke M, Walter J, Schirmer H, Hutter J, Sieber MA: Efficacy and safety of lanthanoids as X-ray contrast agents. Eur J Radiol 2011, 80:349-356

40. Tweedle MF, Wedeking P, Kumar K: Biodistribution of radiolabeled, formulated gadopentetate, gadoteridol, gadoterate, and gadodiamide in mice and rats. Invest Radiol 1995, 30:372-380

41. Pietsch $H$, Raschke $M$, Ellinger-Ziegelbauer $H$, Jost $G$, Walter J, Frenzel T, Lenhard D, Hutter J, Sieber MA: The role of residual gadolinium in the induction of nephrogenic systemic fibrosis-like skin lesions in rats. Invest Radiol 2011, 46:48-56

42. Wilcox CS: Effects of tempol and redox-cycling nitroxides in models of oxidative stress. Pharmacol Ther 2010, 126:119-145

43. Nickoloff BJ: The human progenitor cell antigen (CD34) is localized on endothelial cells, dermal dendritic cells, and perifollicular cells in formalin-fixed normal skin, and on proliferating endothelial cells and stromal spindle-shaped cells in Kaposi's sarcoma. Arch Dermatol 1991, 127:523-529

44. Narvaez D, Kanitakis J, Faure M, Claudy A: Immunohistochemical study of CD34-positive dendritic cells of human dermis. Am J Dermatopathol 1996, 18:283-288

45. Weissman IL, Anderson DJ, Gage F: Stem and progenitor cells: origins, phenotypes, lineage commitments, and transdifferentiations. Annu Rev Cell Dev Biol 2001, 17:387-403

46. Bucala R, Spiegel LA, Chesney J, Hogan M, Cerami A: Circulating fibrocytes define a new leukocyte subpopulation that mediates tissue repair. Mol Med 1994, 1:71-81

47. Bellini A, Mattoli S: The role of the fibrocyte, a bone marrow-derived mesenchymal progenitor, in reactive and reparative fibroses. Lab Invest 2007, 87:858-870

48. Nazarian RM, Mandal RV, Kagan A, Kay J, Duncan LM: Quantitative assessment of dermal cellularity in nephrogenic systemic fibrosis: a diagnostic aid. J Am Acad Dermatol 2011, 64:741-747

49. Grant D, Johnsen $H$, Juelsrud A, Lovhaug D: Effects of gadolinium contrast agents in naive and nephrectomized rats: relevance to nephrogenic systemic fibrosis. Acta Radiol 2009, 50:156-169

50. Singer AJ, Clark RA: Cutaneous wound healing. N Engl J Med 1999 , 341:738-746

51. Crestani B, Besnard V, Boczkowski J: Signalling pathways from NADPH oxidase-4 to idiopathic pulmonary fibrosis. Int J Biochem Cell Biol 2011, 43:1086-1089

52. Hecker L, Vittal R, Jones T, Jagirdar R, Luckhardt TR, Horowitz JC, Pennathur S, Martinez FJ, Thannickal VJ: NADPH oxidase-4 mediates myofibroblast activation and fibrogenic responses to lung injury. Nat Med 2009, 15:1077-1081

53. Bondi CD, Manickam N, Lee DY, Block K, Gorin Y, Abboud HE, Barnes JL: NAD(P)H oxidase mediates TGF-beta1-induced activation of kidney myofibroblasts. J Am Soc Nephrol 2010, 21:93-102

54. Block K, Eid A, Griendling KK, Lee DY, Wittrant Y, Gorin Y: Nox4 $\mathrm{NAD}(\mathrm{P}) \mathrm{H}$ oxidase mediates Src-dependent tyrosine phosphorylation of PDK-1 in response to angiotensin II: role in mesangial cell hypertrophy and fibronectin expression. J Biol Chem 2008, 283:2406124076 